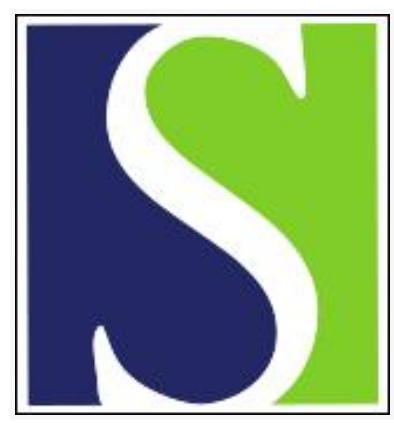

Scand J Work Environ Health 2018;44(3):225-228

https://doi.org/10.5271/sjweh.3727

Published online: 28 Mar 2018, Issue date: 01 May 2018

Shift work and cardiovascular disease - do the new studies add to our knowledge?

by Härmä M, Gustavsson P, Kolstad HA

Affiliation: Research and Service Centre of Occupational Health, Finnish Institute of Occupational Health, Helsinki, Finland. mikko.harma@ttl.fi

Refers to the following texts of the Journal: 2018;44(3):251-257

2018;44(3):229-238 2017;43(2):97-98 2017;43(2):127-135

2017;43(1):59-67 2016;42(6):459-468 2015;41(3):268-279

2013;39(5):431-447 2009;35(3):163-179 1999;25(2):85-99

The following articles refer to this text: 2019;45(5):465-474;

2019;45(3):215-216; 2022;48(1):31-40

Key terms: cardiovascular disease; CHD; coronary heart disease;

CVD; editorial; methodology; selection bias; shift work

This article in PubMed: www.ncbi.nlm.nih.gov/pubmed/29589038 


\section{Shift work and cardiovascular disease - do the new studies add to our knowledge?}

The association of shift work with cardiovascular disease (CVD) has been studied for decades with new systematic reviews repeatedly being published (1-4). Based on 34 studies and over 2 million employees, the systematic review of Vyas et al (4) concluded a few years ago that shift work was associated with incident myocardial infarction, with a risk ratio of 1.23 [95\% confidence interval (CI) 1.15-1.31]. In this issue, a new systematic review and meta-analysis on shift work and the risk of CVD is published. Based on 21 studies, including 10 new ones since the publication of Vyas et al (4), Torquati and colleagues (3) found that shift work was associated with coronary heart disease (CHD) morbidity with a pooled risk ratio of $1.26(95 \% \mathrm{Cl} 1.10-1.43)$ and about $20 \%$ increased risk of death from CHD or CVD. The study also reports that risk of CVD events increased by $7.1 \%$ for every five years of exposure. Even though the classical study of Knutsson et al (5) showed that CVD increases with exposure up to 20 years, the exposure-response estimate based on the meta-analysis is novel.

With the increasing number of original studies and systematic reviews over the years, our knowledge on the association between shift work and CVD should be growing. However, new studies often have old quality problems. Without improvement in quality, new studies may not sufficiently add to the knowledge base. Information and selection bias, insufficient or incorrect control of confounding, and imprecise exposure information have often been common challenges in studies of shift work and CVD $(1,2)$. Thus, we ask whether the quality of new studies reviewed by Torquati et al (3) has improved? And if not, how should future shift work and CVD studies be designed to overcome methodological challenges?

\section{Selection bias}

Earlier studies on shift work and CVD have discussed the possible role of selection, primarily as a source of negative bias, indicating that many may underestimate the true risk. A "healthy shift worker effect" may rise if mainly healthy employees are selected into shift work, for instance based on pre-employment screening or selection out of shift work due to insomnia or other health problems. Both options are possible since health check-ups and regulations for transfer to day work in cases of recognized health problems are included in current legislation in many countries. Since the association between shift work and chronic diseases like CVD and breast cancer attenuates after cessation of exposure $(6,7)$, restricting study populations to elderly cohorts of former shift workers - who have not been exposed for years - may overlook real associations. The recent Million Women Study (8), which found no association between shift work and cancer, included subjects of very advanced age. Starting follow-up at an older age may have resulted in the inclusion of more participants less susceptible to the effects of night shift work $(7,9)$. Furthermore, old age is associated with the accumulation of competing risk factors, diminishing the relative role of shift work compared to the other factors (10).

In the current review, different risks of bias were systematically examined across all individual studies by a validated tool (11). Attrition was not possible to assess in 13 of the 21 published studies, and 1 had clearly a high attrition. If attrition was linked to the full cessation of exposure follow-up in some of the studies, we may have a negative bias of unknown magnitude in some of the published studies.

\section{Exposure assessment}

Already 20 years ago, Bøggild \& Knutsson (1) suggested in their review of shift work and CVD that "different shift schedules should be distinguished to identify which type of shift schedule confers the smallest risk". Torquati et al (3) studied the quality of exposure assessment of the individual studies by analyzing whether information on duration of exposure as well as shift intensity was available, as requested for instance by the International 
Agency for Research on Cancer (IARC) working group report on shift work and cancer studies (12). Torquati et al (3) also investigated the possible use of objective exposure information (payroll or other employer registers or diary data of working hours) of the published studies. Of 21 studies, 8 had additional information on the different elements of shift work exposure and only 4 could provide objective data on shift work exposure. The lack of life-time information on shift work could bias the evaluation of shift work health effects since this may mean that risks of long-term or early shift work exposure is overlooked. In addition, it is common that many day workers are exposed to shift work in the beginning of their career (13); thus, lack of information of earlier exposure attenuates the observed risk estimates.

The use of objective registry-based shift work and health data has several benefits: it provides precise information on exposure less affected by information bias as well as outcome data less affected by attrition since data can be retrieved for all employees (14). However, the main limitations relate to the possibility of accessing company records on longer periods of exposure in addition to obtaining information on exposure outside the main occupation.

\section{Confounding and effect mediators}

Based on Torquati et al (3), all the 21 analyzed studies adjusted for age, body mass index, ethnicity, and socioeconomic status. However, besides increased energy intake (15) and weight gain (16), shift work disturbs sleep and may increase smoking (4). Adjustment for smoking may thus hide a true effect of shift work on smoking-related diseases. A recent study indicated that shift workers had similar leisure-time physical activity patterns as day workers but were more sedentary at work (17). As the authors note, in order to disentangle effect mediation from true confounding, we would need information on these factors not only during the pre-employment period but also repeatedly during and after exposure to shift work.

In their sensitivity analysis, Torquati et al (3) investigated how various sources of potential bias influenced the observed overall risks. Studies were classified as having low, intermediate, or high risk of bias from either unreliable exposure assessment, insufficient adjustment for confounders, analytical methods, blinding of assessors, attrition, selective reporting, or funding. Rather surprisingly, the overall degree of bias had no strong influence on the magnitude of the reported risks, indicating that methodological shortcomings of the studied bias types may not explain the positive overall findings.

However, this may not be the case for the reported positive dose-response relationship with duration of shift work. Of the five studies included in the analysis, three showed increasing risk with duration of shift work (18-20), while two showed no such trend $(21,22)$. The first three studies all relied on self-reported exposure and outcome information that was not blinded to exposure status, while the latter two relied on register information on exposure as well as outcome. For the other eight risk of bias parameters, all five studies were assessed as being equal. This actually questions the reliability of the reported $7.1 \%$ increasing relative risk per five years of shift work, which may be affected by recall bias and stresses the need for analyses based on objective exposure as well as objective outcome data $(23,24)$.

In conclusion, the present review of Torquati et al (3) shows that even if the number of new publications on shift work and cardiovascular health increases, many of the new studies still include the well-known old sources of bias. Some light is seen in the acknowledgement of the need for better exposure assessment of shift work. The new case-control studies of shift work and breast cancer used interviews to get more precise and relevant information on exposure to night and shift work (7). However, the use of electronic records of working hours would be most optimal. For the cohort studies, we would need to combine the precise information on exposure to shift work with longer and more systematic follow-up. With objective information on shift characteristics, which are robust to differential recall, it may be possible to provide acceptable safety limits for the number of annual or consecutive night shifts for different exposure times and/or risk groups. Therefore, future etiological studies and research into the prevention of CVD risks in shift work needs to be based on the principle of obtaining precise and repeated information on exposure to shift work combined with long registry follow-up and repeated information on confounders and possible mediators. 


\section{References}

1. Bøggild H, Knutsson A. Shift work, risk factors and cardiovascular disease. Scand J Work Environ Health. 1999;25(2):8599. https://doi.org/10.5271/sjweh.410

2. Frost P, Kolstad HA, Bonde JP. Shift work and the risk of ischemic heart disease - a systematic review of the epidemiologic evidence. Scand J Work Environ Health. 2009;35(3):163-79. https://doi.org/10.5271/sjweh.1319

3. Torquati L, Mielke GI, Brown WJ, Kolbe-Alexander T. Shift work and the risk of cardiovascular disease. A systematic review and meta-analysis including dose-response relationship. Scand J Work Environ Health. 2018:44(3):229-238. https://doi.org/10.5271/sjweh.3700

4. Vyas MV, Garg AX, Iansavichus AV, Costella J, Donner A, Laugsand LE, et al. Shift work and vascular events: systematic review and meta-analysis. BMJ. 2012;345:e4800. https://doi.org/10.1136/bmj.e4800

5. Knutsson A, Akerstedt T, Jonsson BG, Orth-Gomer K. Increased risk of ischaemic heart disease in shift workers. Lancet. 1986;2(8498):89-92. https://doi.org/10.1016/S0140-6736(86)91619-3

6. Virkkunen H, Härmä M, Kauppinen T, Tenkanen L. The triad of shift work, occupational noise, and physical workload and risk of coronary heart disease. Occup Environ Med. 2006;63(6):378-86. https://doi.org/10.1136/oem.2005.022558

7. Cordina-Duverger E, Menegaux F, Popa A, Rabstein S, Harth V, Pesch B, et al. Night shift work and breast cancer: a pooled analysis of population-based case-control studies with complete work history. Eur J Epidemiol. 2018. https://doi. org/10.1007/s10654-018-0368-x

8. Travis RC, Balkwill A, Fensom GK, Appleby PN, Reeves GK, Wang XS, et al. Night Shift Work and Breast Cancer Incidence: Three Prospective Studies and Meta-analysis of Published Studies. J Natl Cancer Inst. 2016;108(12).https:// doi.org/10.1093/jnci/djw169

9. Applebaum KM, Malloy EJ, Eisen EA. Left truncation, susceptibility, and bias in occupational cohort studies. Epidemiology. 2011;22(4):599-606. https://doi.org/10.1097/EDE.0b013e31821d0879

10. Knutsson A. Mortality of Shift Workers. Scand J Work Environ Health. 2017;43(2):97-8. https://doi.org/10.5271/ sjweh.3622

11. Ijaz S, Verbeek J, Seidler A, Lindbohm ML, Ojajarvi A, Orsini N, et al. Night-shift work and breast cancer--a systematic review and meta-analysis. Scand J Work Environ Health. 2013;39(5):431-47. https://doi.org/10.5271/sjweh.3371

12. Stevens RG, Hansen J, Costa G, Haus E, Kauppinen T, Aronson KJ, et al. Considerations of circadian impact for defining 'shift work' in cancer studies: IARC Working Group Report. Occup Environ Med. 2011;68(2):154-62. https://doi. org/10.1136/oem.2009.053512

13. Härmä M, Koskinen A, Ropponen A, Puttonen S, Karhula K, Vahtera J, et al. Validity of self-reported exposure to shift work. Occup Environ Med. 2017;74(3):228-30. https://doi.org/10.1136/oemed-2016-103902

14. Härmä M, Ropponen A, Hakola T, Koskinen A, Vanttola P, Puttonen S, et al. Developing register-based measures for assessment of working time patterns for epidemiologic studies. Scand J Work Environ Health. 2015;41(3):268-79. https:// doi.org/10.5271/sjweh.3492

15. Hulsegge G, Boer JM, van der Beek AJ, Verschuren WM, Sluijs I, Vermeulen R, et al. Shift workers have a similar diet quality but higher energy intake than day workers. Scand J Work Environ Health. 2016;42(6):459-68. https://doi.org/10.5271/sjweh.3593

16. Buchvold HV, Pallesen S, Waage S, Bjorvatn B. Shift work schedule and night work load: Effects on body mass index - a four-year longitudinal study. Scand J Work Environ Health. 2018. https://doi.org/10.5271/sjweh.3702

17. Hulsegge G, Gupta N, Holtermann A, Jorgensen MB, Proper KI, van der Beek AJ. Shift workers have similar leisure-time physical activity levels as day workers but are more sedentary at work. Scand J Work Environ Health. 2017;43(2):127-35. https://doi.org/10.5271/sjweh.3614

18. Brown DL, Feskanich D, Sanchez BN, Rexrode KM, Schernhammer ES, Lisabeth LD. Rotating Night Shift Work and the Risk of Ischemic Stroke. Am J Epidemiol. 2009. https://doi.org/10.1093/aje/kwp056

19. Gu F, Han J, Laden F, Pan A, Caporaso NE, Stampfer MJ, et al. Total and cause-specific mortality of U.S. nurses working rotating night shifts. American journal of preventive medicine. 2015;48(3):241-52. https://doi.org/10.1016/j. amepre.2014.10.018

20. Vetter C, Devore EE, Wegrzyn LR, Massa J, Speizer FE, Kawachi I, et al. Association Between Rotating Night Shift Work and Risk of Coronary Heart Disease Among Women. Jama. 2016;315(16):1726-34. https://doi.org/10.1001/ jama.2016.4454

21. Yong M, Nasterlack M, Germann C, Lang S, Oberlinner C. Shift work and risk of non-cancer mortality in a cohort of German male chemical workers. Int Arch Occup Environ Health. 2014;87(7):763-73. https://doi.org/10.1007/s00420-0130922-5

22. Yadegarfar G, McNamee R. Shift work, confounding and death from ischaemic heart disease. Occup Environ Med. 2008;65(3):158-63. https://doi.org/10.1136/oem.2006.030627

23. Härmä M, Karhula K, Puttonen S, Ropponen A, Koskinen A, Ojajärvi A, et al. Shift work with and without night work as a risk factor for fatigue and changes in sleep length: A cohort study with linkage to records on daily working hours. J Sleep Res - ePub ahead of print. 
24. Vistisen HT, Garde AH, Frydenberg M, Christiansen P, Hansen AM, Andersen J, et al. Short-term effects of night shift work on breast cancer risk: a cohort study of payroll data. Scand J Work Environ Health. 2017;43(1):59-67. https://doi. org/10.5271/sjweh.3603

Mikko Härmä, Research Professor, MD, PhD,

Research and Service Centre of Occupational Health,

Finnish Institute of Occupational Health,

Helsinki, Finland.

[Email: mikko.harma@ttl.fi]

Per Gustavsson, Senior Professor, MD, PhD,

Institute of Environmental Medicine,

Karolinska Institutet,

Stockholm, Sweden.

[Email: per.gustavsson@ki.se]

Henrik A Kolstad, Professor, MD, PhD,

Department of Clinical Medicine,

Aarhus University,

Aarhus, Denmark.

[Email: henrkols@rm.dk] 